\title{
Anticataleptic potencies of glutamate-antagonists
}

\author{
W. J. Schmidt, B. Zadow, B. D. Kretschmer, and W. Hauber \\ Department Neuropharmacology, University of Tübingen, Federal Republic of Germany
}

Summary. The anticataleptic effects of non-competitive and competitive NMDA antagonists as well as those of an agonist at the allosteric glycine binding site of the NMDA receptor were tested in the catalepsy model. Some of these drugs were further tested in a reaction time task demanding rapid locomotor initiation. The results show that the non-competitive NMDA antagonists dizocilpine and memantine as well as the competitive antagonists CGP 39551, CGP 37849 and CPPene antagonized dopamine $\mathrm{D} 2$ receptor mediated catalepsy induced by haloperidol. D-cycloserine, a partial glycine agonist per se had no effects, but it enhanced the anticataleptic effects of dizocilpine when coadministered. However, the effects of CGP 37849 were abolished. Dopamine D1 receptor mediated catalepsy induced by SCH 23390 was antagonized by dizocilpine, memantine, CPPene, but not by CGP 37849. In the reaction time task dizocilpine, memantine and CGP 37849 were tested for their anti-akinetic and anti-bradykinetic potencies. All these compounds improved haloperidolinduced slowing of reaction time. However, they acted differentially on haloperidol-induced slowing of movement execution and decreased initial acceleration. Thus, antagonists at the NMDA receptor may have a therapeutic potential in the treatment of Parkinson's disease. Their potency can be manipulated specifically at the glycine binding site.

Keywords: Amino acids - Catalepsy - Movement initiation - NMDA antagonists - Glycine - Parkinson's disease - Rat

\section{Introduction}

Glutamate is considered to be the main transmitter mediating synaptic excitation in the mammalian brain. There exist at least three receptor subtypes for glutamate, one of which is the N-methyl-D-aspartate (NMDA) receptor. The NMDA receptor can be manipulated pharmacologically with drugs acting directly and competitively with respect to NMDA, at the NMDA binding site (NMDA as an agonist and AP-5, CGP 37849 and CGP 35991 as competitive antagonists). The NMDA binding site gates a cation channel which can be blocked by drugs - when in its open state - non-competitively with respect to 
NMDA (dizocilpine [MK-801], memantine). Additionally a strychnine-insensitive glycine binding site exists that facilitates the excitation mediated by the NMDA binding site (D-cycloserine acts as an agonist at the glycine binding site) (Johnson and Ascher, 1987; Hood et al., 1989; Watson et al., 1990).

With respect to the behavioural pharmacology of NMDA antagonists, it has been found that competitive (Morris et al., 1986) as well as non-competitive NMDA antagonists (Danysz and Wroblewski, 1989) induce impairments in place learning of rats. In the radial 8-arm-maze dizocilpine specifically impaired working memory while reference memory remained intact (Schmidt and Bischoff, 1988). With local injections and lesion techniques it has been shown that disruption of glutamatergic transmission in the hippocampus (Morris et al., 1986; Hölscher and Schmidt, 1991) is critically involved in this form of learning. Besides their effects on learning, NMDA antagonists induce a characteristic psychomotor stimulation syndrome, e.g. continuous locomotion and sniffing (Carlsson and Carlsson, 1990; Tiedtke et al., 1990). The non-competitive antagonists are much more effective in this regard. Local injections of AP-5 (Schmidt, 1986), dizocilpine (Imperato, 1991) or NMDA (Schmidt and Bury, 1988 ) into the striatum of rats reveal this structure to mediate locomotion and sniffing. Interestingly AP-5 infusion into the striatum does not affect learning (Hauber and Schmidt, 1989).

It is well known that, within the striatum, dopamine (DA) agonists also induce behavioural activation. Thus, it has been concluded that a population of striatal output neurons (probably medium sized GABAergic spiny neurons) may exist onto which dopamine and glutamate via the NMDA receptor exert opposite effects (Schmidt et al., 1990).

Blockade of central dopaminergic neurotransmission by dopamine receptor antagonists produces selective motor impairments in rats. These impairments seem to be predominantly due to the animals inability to initiate motor behaviour (Skjoldager and Fowler, 1988). This hypothesis is based on findings of neuroleptic-treated animals showing akinesia and rigidity (catalepsy), prolonged reaction times (RT) and further motor impairments in various other behavioural paradigms (e.g. Amalric and Koob, 1987; Skjoldager and Fowler, 1988). Since these motor impairments reflect in part symptoms of Parkinson's disease (akinesia, rigidity, tremor), neuroleptic-induced akinesia and rigidity is considered to be an animal model of this disease.

In the present study it was investigated whether or not antagonists at the NMDA receptor are able to compensate the behavioural effects of a reduced dopaminergic activity. Furthermore, the modulation of these effects by a glycine agonist were investigated.

The behavioural effects were examined in two different models. First, we used the catalepsy test where a state of postural immobility, i.e. akinesia, rigidity, was induced by administration of haloperidol and possible anticataleptic effects of concurrent modulation of the NMDA receptor could be detected.

Some of the NMDA antagonists found to be effective in the catalepsy test, were further investigated in a newly developed reaction time (RT) task for rats, which demands rapid initiation of locomotion in order to get a food reward (Hauber, 1990). Administration of haloperidol has been found to produce selec- 
tive impairments of locomotor initiation in this task: RT was significantly slowed and the initial acceleration of the movement was decreased as measured by the rate of force development (FS). Furthermore, the movement time (MT) was prolonged (Hauber and Schmidt, 1990). This pattern of impairments is reminiscent to akinesia and bradykinesia in patients with Parkinson's disease. According to the distinction of Hallett (1990) akinesia refers to delayed movement initiation and is characterized by a prolongation of RT. Bradykinesia refers to slowness of ongoing movement and is characterized by a prolongation of MT and a decrease of the dynamic indices of a movement (Stelmach and Worringham, 1988; Wierzbicka et al., 1991).

The RT task used here is sensitive to possible beneficial effects of compounds on movement initiation deficits following administration of haloperidol, since anti-akinetic (change of RT) and anti-bradykinetic (change of MT and FS) of a compound could be detected.

\section{Materials and methods}

\section{Subjects}

Subjects were male Sprague Dawley rats (Interfauna, F. R. G.) caged in groups with free access to water. They were provided with $12 \mathrm{~g} / \mathrm{d} /$ rat rodent laboratory chow (Altromin, $\mathrm{F}$. R. G.) after the daily experimental sessions. The colony room was temperature-regulated $\left(22 \pm 3^{\circ} \mathrm{C}\right)$ and rats were maintained on a $12-12 \mathrm{~h}$ light dark cycle (lights on at $06.00 \mathrm{~h}$ ).

\section{Drugs}

Haloperidol (Janssen, F. R. G.), SCH 23390 (Biotrend, F. R. G.), memantine HCl (Merz, F. R. G.), CGP 39551 (Ciba-Geigy, Switzerland), dizocilpine (MK-801) (Merck, Sharpe \& Dohme, F. R. G.) and D-CPP-ene (SDZ EAA-494) (Sandoz, Switzerland) were dissolved in saline and injected at a maximum volume of $0.5 \mathrm{ml}$. CGP 37849 (Ciba-Geigy, Switzerland) was dissolved in saline and the $\mathrm{pH}$ was adjusted with $0.1 \mathrm{~N} \mathrm{NaOH}$ on 7-7.5. D-Cycloserine (Fluka, F. R. G.) was dissolved in carbonate buffer and adjusted to $\mathrm{pH} 8.1-8.5$. All drugs were given intraperitoneally.

In the catalepsy test the following drug dosing regimen was used: Dopamine D2 receptor mediated catalepsy was induced by administration of haloperidol $(0.5 \mathrm{mg} / \mathrm{kg})$ and the anticataleptic effects of dizocilpine $(0.04,0.16 \mathrm{mg} / \mathrm{kg})$, memantine $(5,10 \mathrm{mg} / \mathrm{kg})$, D-cycloserine (12 mg/kg), CGP $37849(2,4 \mathrm{mg} / \mathrm{kg})$, CGP $39551(5,10 \mathrm{mg} / \mathrm{kg})$ and CPPene $(5 \mathrm{mg} / \mathrm{kg})$ were tested. The effects of combined administration of D-cyloserine $(12 \mathrm{mg} / \mathrm{kg})$ with either dizocilpine $(0.08 \mathrm{mg} / \mathrm{kg})$ or CGP $37849(4 \mathrm{mg} / \mathrm{kg})$ were also investigated. Dopamine D1 mediated catalepsy was induced by administration of SCH $23390(1 \mathrm{mg} / \mathrm{kg})$ and the anticataleptic effects of dizocilpine $(0.16 \mathrm{mg} / \mathrm{kg})$, memantine $(10 \mathrm{mg} / \mathrm{kg})$, CGP 37849 $(4 \mathrm{mg} / \mathrm{kg})$ and CPPene $(5 \mathrm{mg} / \mathrm{kg})$ were examined. The details of the timing of the injections are given in the results section.

In the reaction time task haloperidol $(0.15$ and $0.3 \mathrm{mg} / \mathrm{kg})$, memantine $(10 \mathrm{mg} / \mathrm{kg})$ and CGP $37849(4 \mathrm{mg} / \mathrm{kg})$ were given alone, and haloperidol $(0.15,0.3 \mathrm{mg} / \mathrm{kg})$ in combination with memantine $(10 \mathrm{mg} / \mathrm{kg})$ or CGP $37849(4 \mathrm{mg} / \mathrm{kg})$.

\section{Behavioural procedure}

\section{Catalepsy}

Catalepsy was assessed by measuring the time span from placement of a rat onto a vertical grid until the rat removes one of its paws (descent latency), at the most for $180 \mathrm{~s}$ (Scheel- 
Krüger 1983). The data are presented as means \pm SEM. They were submitted to a one way ANOVA followed by Tukey's protected T-test.

\section{Movement initiation}

The exact details of the apparatus, behavioural procedure and data recording are described elsewhere (Hauber 1990; Hauber and Schmidt, 1990). Briefly, a modified runway was used which consisted of a start box and a runway terminating in a goal box. A trained, gradually food deprived rat was placed in the start box with the face to the guillotine door blocking the entrance to the runway. After a variable delay, a stimulus signalled the simultaneous opening of the front door. In response to the stimulus, a rat initiated from a starting position rapid locomotion and moved through the runway to the goal box to receive a food reward in a food cup (45 $\mathrm{mg}$ pellet, Noyes, U.S.A.). Approximately $30 \mathrm{~s}$ later, the rat was replaced from the goal box into the start box for a new trial. The transition from stance to locomotion was recorded by means of a photoelectronic switch situated in front of the start box and a force platform mounted below the start box.

The following measures were taken from each trial: correct reaction time (RT) defined as latency (valid range: $100-1000 \mathrm{~ms}$ ) between stimulus presentation and photobeam interruption, correct movement time (MT) (valid range 100-1500 ms) defined as latency between photobeam interruption and leaving of the platform and the rate of force development (force slope, FS) of the accelerative force. The time resolution of the device was less than $10 \mathrm{~ms}$.

The trained rats were tested in two daily sessions which consisted of 10 successive trials per animal, respectively. The following experimental design was used: stable baseline performance was established in 10 preexperimental training sessions. Thereafter, the experiment was performed on consecutive days with two successive sessions per day, respectively. The baseline performance of the animals was assessed in the first daily sessions where the animals received saline $(1 \mathrm{ml} / \mathrm{kg}$ i.p.). In the second daily session one $\mathrm{drug} / \mathrm{saline}$ or $\mathrm{drug} / \mathrm{drug}$ combination of a fixed dose was tested in the same animals. Two different groups of naive rats were used to test CGP $37849(4 \mathrm{mg} / \mathrm{kg}$ i.p.) and memantine $(10 \mathrm{mg} / \mathrm{kg}$ i.p. $)$ alone and in combination with haloperidol, respectively.

The results are based on the means of the parameters in correct trials $( \pm S E M)$ per session and calculated as follows: The drug effects following single administration were measured by comparison of group differences between drug session and corresponding saline session from the same animals at the same day and presented as relative change in percent $( \pm S E M)$ of each parameter. The drug effects on haloperidol-induced deficits of the parameters used, were measured by comparisons between sessions with coadministration (haloperidol + drug) and the corresponding haloperidol session (haloperidol given alone at a fixed dose). The drug effect was expressed as relative change in percent $( \pm S E M)$ of the haloperidol effect. Statistical significance of the raw data was calculated by a one-way ANOVA followed by the Tukey's protected T-test. The parameters of the baseline sessions (saline administration) of all days were analyzed by a one-way analysis of variance (ANOVA) to check for stability of baseline performance. The significance level was $p \leq 0.05$. The data were compared with results of an earlier study (Hauber and Schmidt, 1990) where dizocilpine was investigated in the same task using a similar experimental protocol.

\section{Results}

\section{Catalepsy}

Haloperidol, that preferentially blocks D2-dopamine receptors, induced catalepsy which was reduced by the non-competitive NMDA-antagonist dizocilpine $(0.04$ and $0.16 \mathrm{mg} / \mathrm{kg}$ i.p.). Also the adamantan derivative memantine (5 and 10 $\mathrm{mg} / \mathrm{kg}$ i.p.) reduced haloperidol-induced catalepsy (Table 1). 


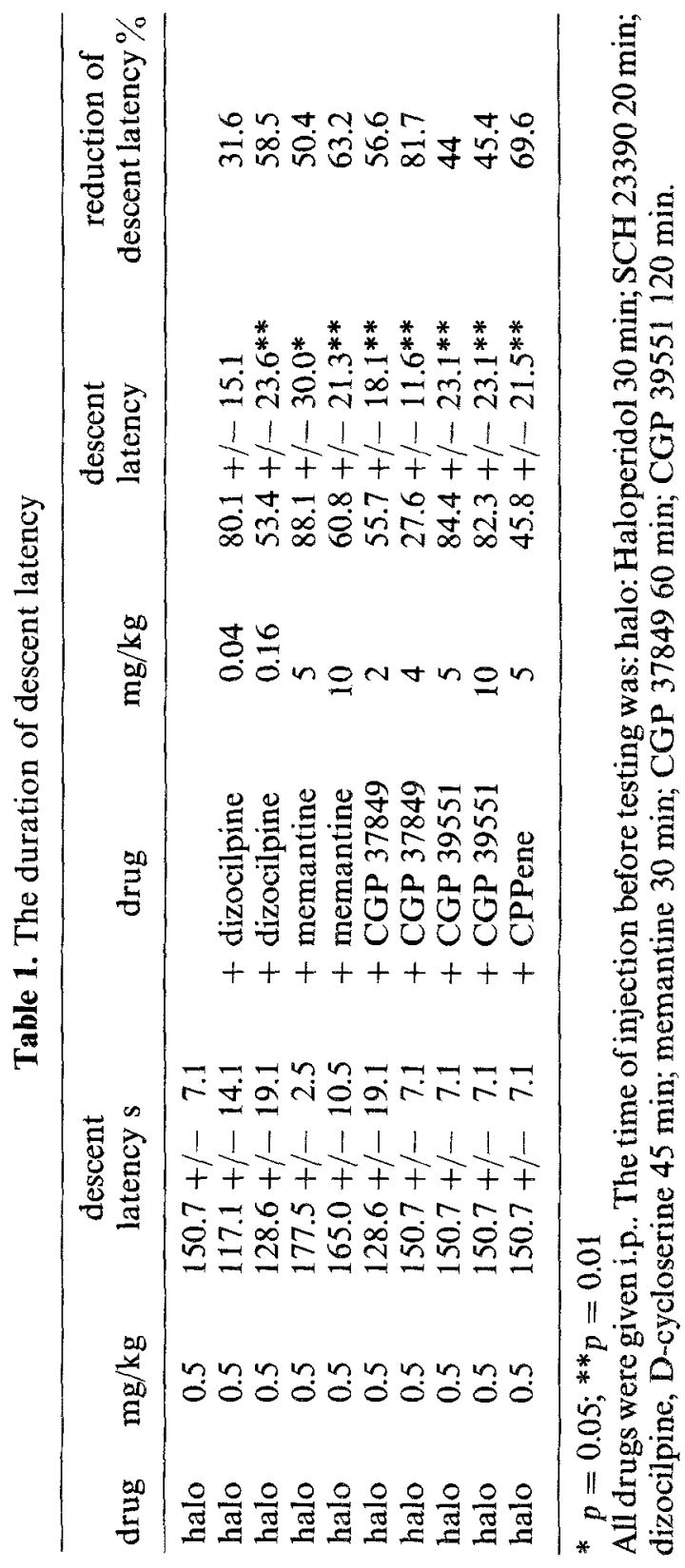


W. J. Schmidt et al.
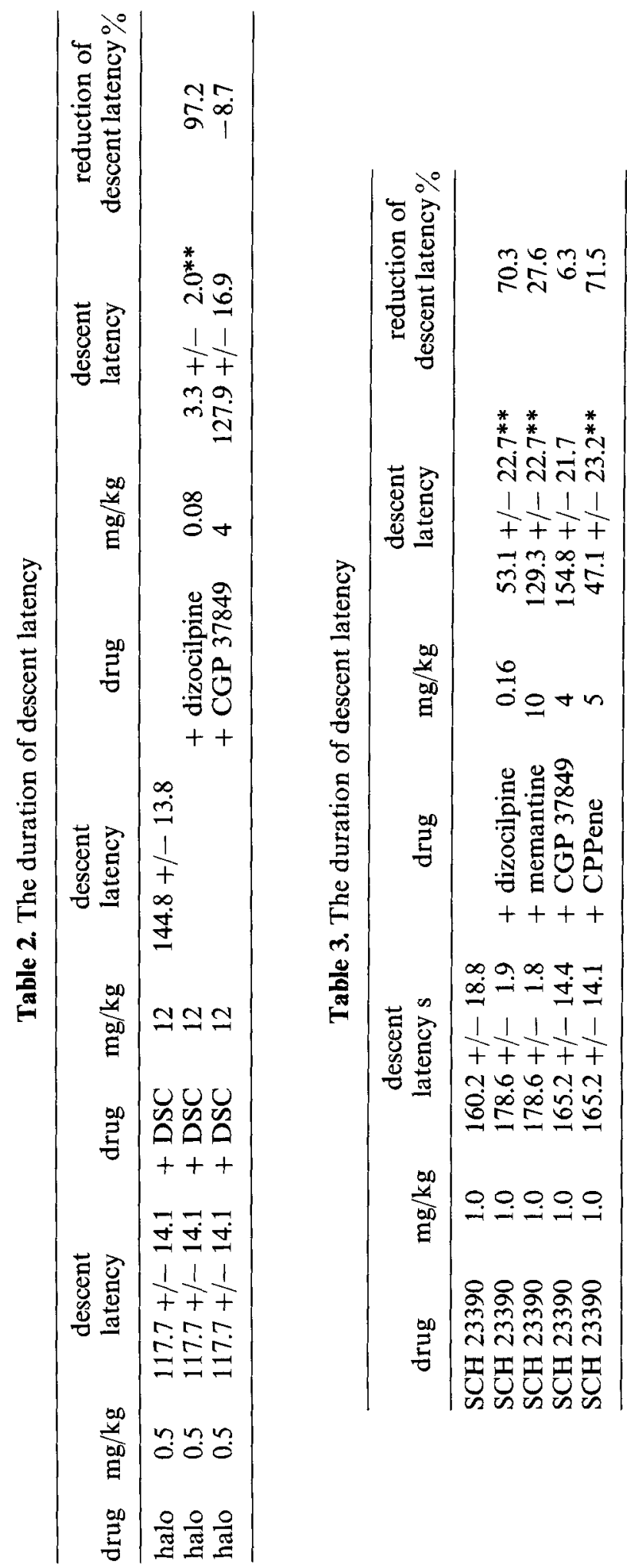
Likewise, the competitive NMDA antagonists CGP 37849 (2 and $4 \mathrm{mg} / \mathrm{kg}$ i.p.), CGP 39551 (5 and $10 \mathrm{mg} / \mathrm{kg}$ i.p.) and CPPene $(5 \mathrm{mg} / \mathrm{kg}$ i.p.) reduced catalepsy as well (Table 1). However, the glycine agonist D-cycloserine $(12 \mathrm{mg} / \mathrm{kg}$ i.p.) interacted very differently with non-competitive and competitive NMDA antagonists: while the anticataleptic effects of the non-competitive NMDA antagonist were even strengthened, those of the competitive antagonist were completely abolished (Table 2).

The D1-dopamine receptor blocker SCH 23390, at a dose of $1 \mathrm{mg} / \mathrm{kg}$ i.p., induced catalepsy to a similar degree as haloperidol $(0.5 \mathrm{mg} / \mathrm{kg}) \mathrm{did}$. The noncompetitive NMDA-antagonists dizocilpine $(0.16 \mathrm{mg} / \mathrm{kg}$ i.p.) and memantine $(10 \mathrm{mg} / \mathrm{kg}$ i.p.) antagonized SCH 23390 -induced catalepsy. However, the competitive antagonists had inconsistent effects: while CGP 37849 did not reduce SCH 23390-induced catalepsy, CPPene exerted a pronounced anticataleptic effect (Table 3).

\section{Movement initiation}

The baseline performance of both groups of animals remained nearly constant on all parameters over all days $(p>0.05$ for each parameter, ANOVA, data not shown). In addition, comparison of two saline sessions performed on the same day showed little variability of the parameters (see Fig. 1). Thus, a possible influence of days or session on drug-induced effects could be neglected.

Haloperidol, given alone, caused dose dependently a slowing of RT (akinesia) and a profound bradykinesia as indicated by a reduced initial acceleration (decrease of FS) and prolonged MT (Fig. 1). Memantine caused a slight and significant slowing of RT and impaired initial movement execution powerfully. The impairments of MT and FS were about the same degree than those induced by haloperidol, but were most possibly due to the muscle relaxant properties of memantine. CGP 37849 did not alter RT and MT, but reduced initial acceleration. By contrast, dizocilpine (data from Hauber and Schmidt, 1990) induced marked stimulatory effects on movement execution, but left RT unchanged.

The anti-akinetic effects of these compounds, examined by coadministration with haloperidol, showed that memantine, CGP 37849 and dizocilpine antagonized the haloperidol-induced slowing of RT (Fig. 2 and 3), respectively. At both doses of haloperidol the rank order of potency was the same with dizocilpine as the most effective compound followed by CGP 37849 and memantine.

With regard to the reversal of haloperidol-induced bradykinesia, i.e. decrease of FS and increase of MT, marked differences between these drugs were found (Fig. 2 and 3). Memantine did not antagonize bradykinetic effects, the prolongation of MT was even worsened at the lower dose of haloperidol and not improved at the higher dose of haloperidol. The decrease of FS was not altered at both doses. CGP 37849 improved the haloperidol-induced MT deficit, but did not increase deficient FS at both doses, respectively. Dizocilpine antagonized the MT prolongation markedly and, above all, increased initial acceleration at both doses. 


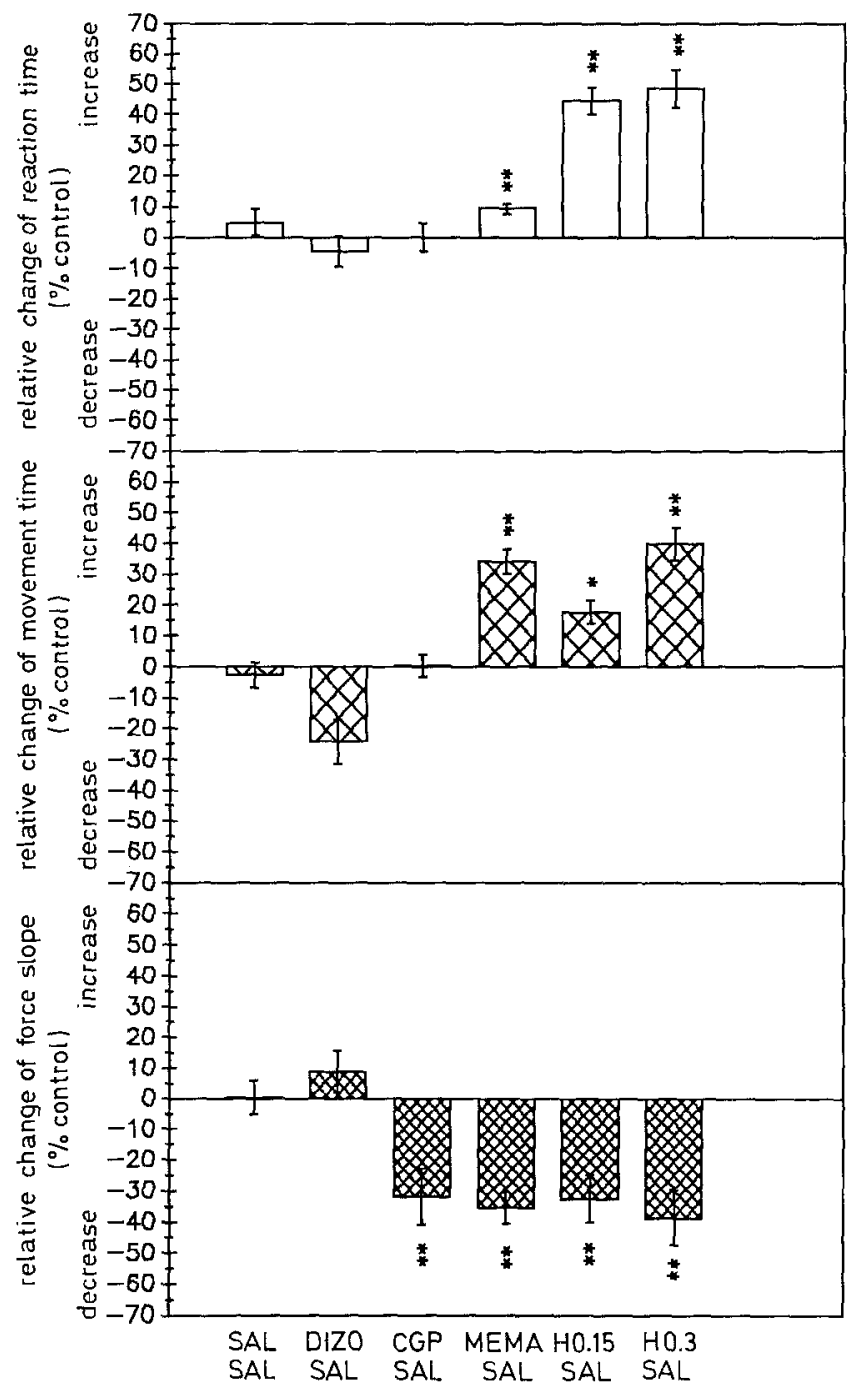

Fig. 1. Effects of single administration (i.p.) of saline (SAL: $1 \mathrm{ml} / \mathrm{kg}$ ), dizocilpine (DIZO: 0.08 $\mathrm{mg} / \mathrm{kg}$ ), CGP 37849 (CGP: $4 \mathrm{mg} / \mathrm{kg}$ ) memantine (MEMA: $10 \mathrm{mg} / \mathrm{kg}$ ) and haloperidol (H0.15: $0.15 \mathrm{mg} / \mathrm{kg} ; \mathrm{H} 0.3: 0.3 \mathrm{mg} / \mathrm{kg}$ ) on reaction time (top), movement time (middle) and force slope (bottom). The drug effects were measured for each parameter $(n=68-100)$ by comparison of mean group differences between drug session and according saline session of the same animals $(N=8-10)$ at the same day and presented as relative change in percent $( \pm \mathrm{SEM})\left({ }^{*} p<0.05,{ }^{* *} p<0.01\right.$, ANOVA followed by Tukey's protected T-test).

(Dizocilpine data are from Hauber and Schmidt, 1990)

Thus, dizocilpine, memantine and CGP 39849 had pronounced anti-akinetic effects on haloperidol-induced slowing of RT. With respect to haloperidolinduced bradykinesia, only dizocilpine reversed impairments of MT and FS. CGP 37849 improved selectively prolonged MT, but left the deficient initial acceleration unchanged. Memantine had no anti-bradykinetic effects, but had muscle relaxant properties which caused most probably impairments of movement initiation which are also prominent when coadministered together with haloperidol. 


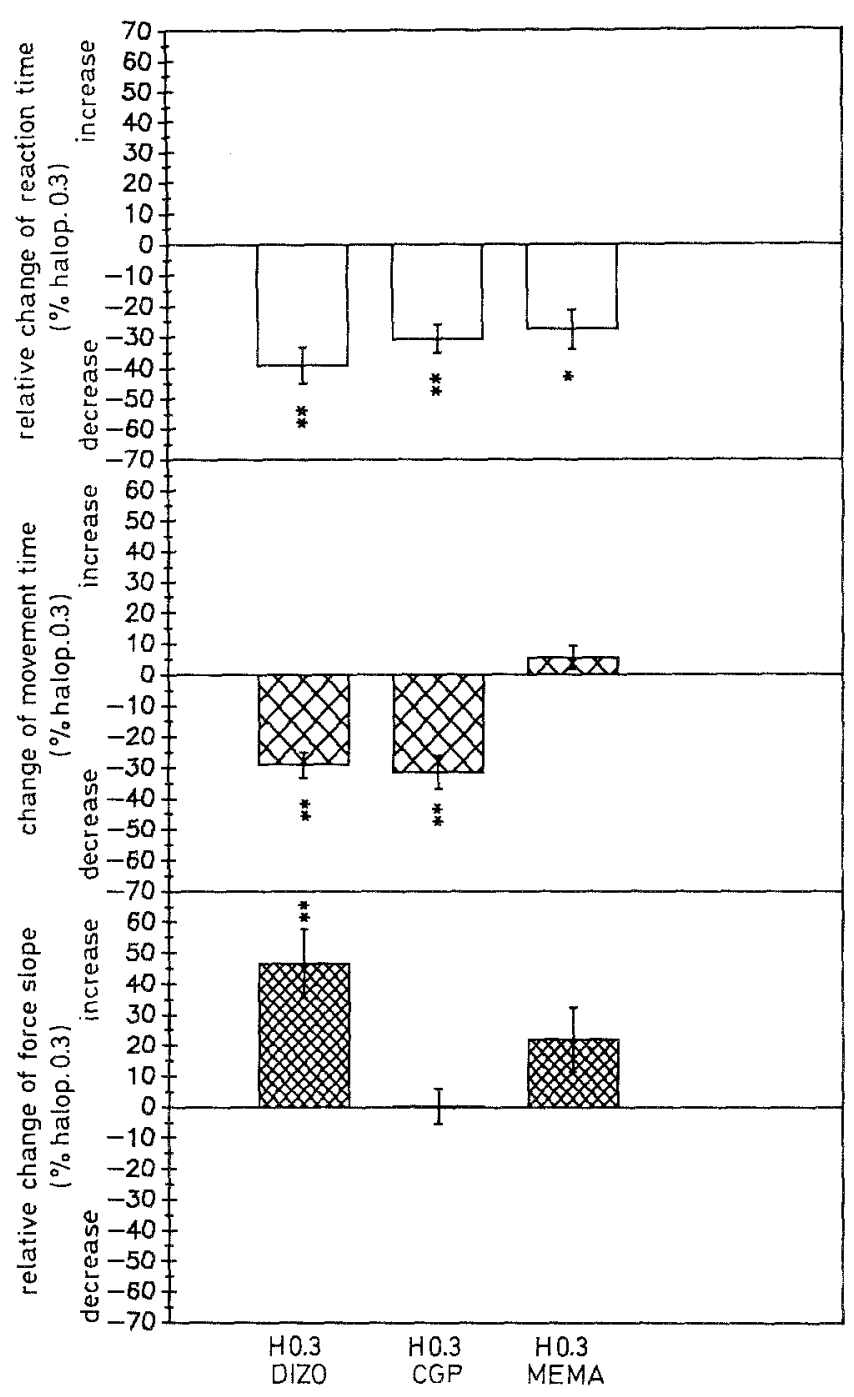

Fig. 2. Effects of dizocilpine (DIZO: $0.08 \mathrm{mg} / \mathrm{kg}$ ), CGP 37849 (CGP: $4 \mathrm{mg} / \mathrm{kg}$ ) or memantine (MEMA: $10 \mathrm{mg} / \mathrm{kg}$ ) administration (i.p.) on haloperidol-induced deficits $(0.15 \mathrm{mg} / \mathrm{kg}$ ) of reaction time (top), movement time (middle) and force slope (bottom). The drug effects on haloperidol-induced deficits of the parameters were measured by comparison of mean group differences between sessions with coadministration (haloperidol $0.15 \mathrm{mg} / \mathrm{kg}+$ drug) and the according haloperidol session (haloperidol $0.15 \mathrm{mg} / \mathrm{kg}) .(N=8-10, n=29-97$ for each parameter and session). The drug effect was expressed as relative change in percent $( \pm S E M)$ of the haloperidol effect $\left(^{*} p<0.05,{ }^{* *} p<0.01\right.$, ANOVA followed by Tukey's protected

T-test). (Dizocilpine data are from Hauber and Schmidt, 1990)

\section{Discussion}

The main findings of the present study are, that the non-competitive NMDA antagonists dizocilpine and memantine as well as the competitive antagonists CGP 37849, CGP 39551 and CPPene antagonized D2 mediated catalepsy induced by haloperidol. In addition, an enhancement of the anticataleptic effect of dizocilpine by D-cycloserine, but not of CGP 37849 by D-cycloserine, was 
W. J. Schmidt et al.

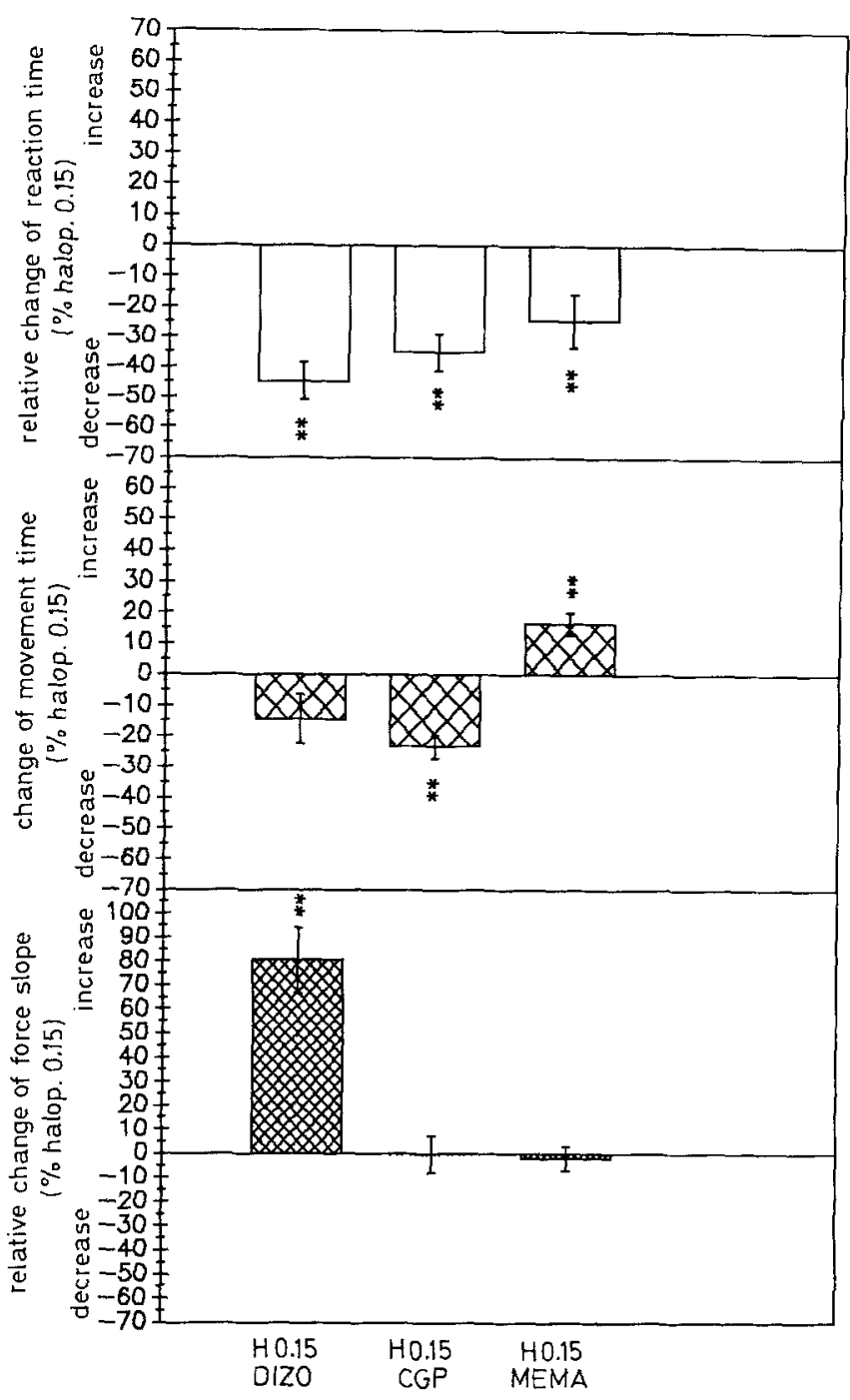

Fig. 3. Effects of dizocilpine (DIZO: $0.08 \mathrm{mg} / \mathrm{kg}$ ), CGP 37849 (CGP: $4 \mathrm{mg} / \mathrm{kg}$ ) or memantine (MEMA: $10 \mathrm{mg} / \mathrm{kg}$ ) administration (i.p.) on haloperidol-induced deficits $(0.3 \mathrm{mg} / \mathrm{kg}$ ) of reaction time (top), movement time (middle) and force slope (bottom). The drug effects on haloperidol-induced deficits of the parameters were measured by comparison of mean group differences between sessions with coadministration (haloperidol $0.3 \mathrm{mg} / \mathrm{kg}+\mathrm{drug}$ ) and the according haloperidol session (haloperidol $0.3 \mathrm{mg} / \mathrm{kg}) .(N=8-10, n=73-100$ for each parameter and session). The drug effect was expressed as relative change in percent ( \pm SEM) of the haloperidol effect $\left({ }^{*} p<0.05,{ }^{* *} p<0.01\right.$, ANOVA followed by Tukey's protected T-test). (Dizocilpine data are from Hauber and Schmidt, 1990)

found in this test. D1 mediated catalepsy induced by SCH 23390 was antagonized by dizocilpine, memantine, CPPene, but not by CGP 37849 . Besides this static task, dizocilpine, memantine and CGP 37849 were tested in a dynamic task to assess their anti-akinetic and anti-bradykinetic potencies. It was found that all these compounds improved haloperidol-induced slowing of reaction time. However, slowing of movement execution and decreased initial acceleration was differentially reversed. 
There is now general agreement, that dizocilpine has stimulant effects, e.g. it enhances locomotion and sniffing (Clineschmidt et al., 1982; Tiedtke et al., 1990). Also direct infusion of dizocilpine into the striatum causes these effects (Imperato et al., 1990). Further, dizocilpine antagonizes haloperidol-induced catalepsy (Schmidt and Bubser, 1989; Elliot et al., 1990) and had the most pronounced anti-akinetic and anti-bradykinetic properties of the substances tested in the RT task. The present findings corroborate the previous studies and additionally show an antagonism of dizocilpine against SCH 23390-induced catalepsy.

The studies of Imperato et al. (1991a) show that dizocilpine enhances dopamine release and turnover within the striatum and the nucleus accumbens. Thus it may be argued that enhanced locomotion and its anticataleptic effects are due to this indirect effect of dizocilpine and not primarily by its interaction with the NMDA receptors. However, several findings argue against this view: I. In saline treated rats the dopamine metabolism (DOPAC/DA ratio) in nucleus accumbens correlates with locomotor activity. But in dizocilpine treated rats, locomotion is not correlated with DOPAC/DA ratio in the accumbens (Keseberg et al., 1991). II. in mice depleted of dopamine by reserpine and $\alpha$-methyl-paratyrosine, dizocilpine still produces locomotor stimulation (Carlsson and Carlsson, 1990).

In the striatum, glutamate via the NMDA receptor seems to exert depressant effects on behaviour. This view is supported by the finding that NMDA, when injected directly into the striatum reduces locomotion, sniffing, rearing and feeding (Schmidt and Bury, 1988). Given systemically, it enhances haloperidolinduced catalepsy (Mehta and Ticku, 1990) but does not change dopamine release (Imperato et al., 1990a). Dopamine release in the striatum and in the nucleus accumbens seems to be controlled by non-NMDA receptors (Imperato et al., 1990b) in vivo.

The present data are not entirely consistent with data obtained form in vitro models. However, as discussed by Liljequist et al. (1991), a comparison is difficult since in vivo many additional regulatory mechanisms participate in transmitter release and uptake.

Memantine, which is an adamantan derivative with spasmolytic and antiparkinsonian actions, antagonized haloperidol- and SCH 23390-induced catalepsy. The dopamine-mimetic effect of memantine is not pronounced enough to account for its anticataleptic effect. Thus, the recently described non-competitive blockade of the NMDA receptor (Bormann et al., 1989; Kornhuber et al., 1989) may explain its efficacy in the catalepsy model as well as the anti-akinetic effects in the RT task. The spasmolytic properties of memantine are most probably the reason for the lacking effects on movement execution in the RT task.

Also the competitive NMDA antagonists antagonized haloperidol-induced catalepsy (Table 1). However, this is not the case for SCH 23390-induced catalepsy: While CPPene antagonized SCH 23390-induced catalepsy, CGP 37849 was completely ineffective (Table 3). At present, we have no explanation for this. In addition CGP 37849 was found to have pronounced anti-akinetic effects, but had, in comparison to dizocilpine, less marked anti-bradykinetic effects. 
Stimulation of the glycine binding site enhanced the anticataleptic effects of dizocilpine (Table 3). This is in accordance with electrophysiological and receptor-binding studies showing an increase in binding of channel blockers - such as dizocilpine - when the glycine binding site is stimulated (Wong et al., 1987). However, CGP 37849, which per se has anticataleptic potency, loses its potency when combined with D-cycloserine (Table 3). Although this effect cannot be explained, it is tempting to speculate, along with some evidence from the literature (Monaghan et al., 1988) that stimulation of the glycine binding site converts the competitive NMDA binding site in its agonist preferring conformation, thus preventing the binding of the competitive antagonists.

In conclusion, the present study shows that NMDA antagonists exert anticataleptic effects in the rat and thus may have a therapeutic potential in the treatment of Parkinson's disease. This study also shows in which way the various binding sites of the NMDA receptor contribute to the expression of behaviour. This may help in the search for drugs with minimal side effects but with the desired specificity against Parkinson's disease.

\section{Acknowledgement}

We thank the Deutsche Forschungsgemeinschaft (SFB 307) for financial support and the companies for kindly providing the drugs.

\section{References}

1. Amalric M, Koob GF (1987) J Neurosci 7/7: 2129-2134

2. Bormann J (1989) Eur J Pharmacol 166: 591-592

3. Carlsson M, Carlsson A (1990) Trends Neurosci 13/7:272-280

4. Clineschmidt BV, Martin GE, Bunting PR, Papp NL (1982) Drug Dev Res 2: 135-145

5. Danysz W, Wroblewski JT (1989) Neurosci Res Comm 5: 9-18

6. Elliott PJ, Close SP, Walsh DM, Hayes AG, Marriott AS (1990) J Neural Transm 2: $91-100$

7. Hallett M (1990) Rev Neurol (Paris) 146/10:585-590

8. Hauber W, Schmidt WJ (1989) J Neural Transm 78: 29-41

9. Hauber W (1990) Experientia 46: 1083-1088

10. Hauber W, Schmidt WJ (1990) Behav Brain Res 41: 161-166

11. Hölscher C, Schmidt WJ (1991) In: Elsner N, Penzlin H (eds) Synapse - Transmission modulation. Proceedings of the 19th Göttingen Neurobiology Conference, Göttingen 1991, Thieme, Stuttgart New York (Abstr 450)

12. Hood WF, Compton RP, Monhan JB (1989) Neurosci Lett 98: 91-95

13. Imperato A, Scrocco MG, Bacchi S, Angelucci L (1990a) Eur J Pharmacol 187: 555-556

14. Imperato A, Honore T, Jensen LH (1990b) Brain Res 530: 223-228

15. Johnson JW, Ascher P (1987) Nature 325: 529

16. Keseberg U, Bubser M, Schmidt WJ (1991) In: Elsner N, Penzlin H (eds) Synapse Transmission modulation. Proceedings of the 19th Göttingen Neurobiology Conference, Göttingen 1991, Thieme, Stuttgart New York (Abstr 448)

17. Kornhuber J, Bormann J, Retz W, Hübers M, Riederer P (1989) Eur J Pharmacol 166: 589-590

18. Liljequist S, Ossowska K, Grabowska-Andén M, Andén N-E (1991) Eur J Pharmacol 195: 55-61

19. Mehta AK, Ticku MK (1990) Life Sci 46: 37-42

20. Monaghan DT, Olverman HJ, Nguyen L, Watkins JC, Cotman CW (1988) Proc Nat1 Acad Sci USA 85: 9836 
21. Morris RGM, Anderson E, Lynch GS, Baudry M (1986) Nature 319: 774

22. Scheel-Krüger J (1983) In: Enna EJ (ed) Humana Press Clifton, pp 215-256

23. Schmidt WJ (1986) Psychopharmacology 90: 123-130

24. Schmidt WJ, Bischoff C (1988) Psychopharmacology 96: 51

25. Schmidt WJ, Bury D (1988) Life Sci 43/6: 545-549

26. Schmidt WJ, Bubser M (1989) Pharmacol Biochem Behav 32: 621-623

27. Schmidt WJ, Bubser M, Hauber W (1990) Trends Neurosci 13/2: 46

28. Skjoldager P, Fowler SC (1988) Psychopharmacology 96: 21-28

29. Stelmach GE, Worringham CJ (1988) Neuropsychologia 26: 93-103

30. Tiedtke PI, Bischoff C, Schmidt WJ (1990) J Neural Transm 81: 173-182

31. Watson GB, Bolanowski MA, Boganoff MP, Deppeler CL, Lanthorn TH (1990) Brain Res 510: $158-160$

32. Wierzbicka MM, Wiegner AW, Logigian EL, Young RR (1991) J Neurol Neurosurg Psychiatry 54: 210-216

33. Wong EHF, Knight AR, Ransom R (1987) Eur J Pharmacol 142: 487-488

Authors' address: Dr. W. J. Schmidt, University of Tübingen, Department Neuropharmacology, Mohlstrasse 54/1, D-W-7400 Tübingen, Federal Republic of Germany. 